
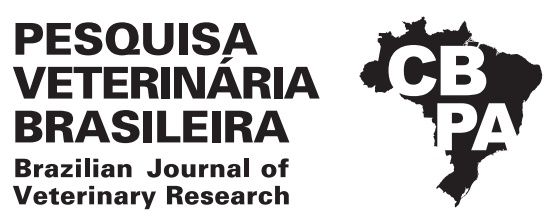

Pesq. Vet. Bras. 38(9):1856-1862, setembro 2018 DOI: 10.1590/1678-5150-PVB-5449

Artigo Original

ISSN 0100-736X (Print)

ISSN 1678-5150 (Online)

\title{
Avaliação da lactatemia e das enzimas musculares de equinos Quarto de Milha submetidos à prova de laço em dupla com diferentes tipos de treinamento ${ }^{1}$
}

\author{
Mariana S. Pereira ${ }^{2 *}$, Bianca Gerardi ${ }^{2}$, Daniela S. Denadai ${ }^{2}$, Arthur A. Chaves ${ }^{2}$, \\ João P.B. Barbosa² ${ }^{2}$ José E.O. Zanon², Lina Maria W. Gomide ${ }^{2}$ e Luiz Claudio N. Mendes ${ }^{2}$
}

\begin{abstract}
Pereira M.S., Gerardi B., Denadai D.S., Chaves A.A., Barbosa J.P.B., Zanon J.E.O., Gomide L.M.W. \& Mendes L.C.N. 2018. [Evaluation of lactatemia and muscle enzymes in Quarter Horses subjected to team ropping with different types of training.] Avaliação da lacatatemia e das enzimas musculares de equinos Quarto de Milha submetidos à prova de laço em dupla com diferentes tipos de treinamento. Pesquisa Veterinária Brasileira 38(9):1856-1862. Departamento de Clínica, Cirurgia e Reprodução Animal, Faculdade de Medicina Veterinária, Universidade Estadual Paulista, Campus de Araçatuba, Rua Clóvis Pestana 793, Bairro Dona Amélia, Araçatuba, SP 16050-680, Brazil. E-mail: marijeronymo@hotmail.com

The aim of this study was to evaluate the influence of different types of training on physical fitness through the determination of blood lactate and serum creatinine kinase, aspartate aminotransferase, and lactate dehydrogenase activity after high intensity and short duration physical exercise. Venous blood samples were obtained from 16 Quarter Horses, divided into two groups: the regular training group (GTR) and sporadic training group (GTE), in seven different moments: 30 minutes before exercise (M0), immediately after the exercise (M1), 30 minutes (M2), one hour (M3), two hours (M4), six hours (M5) and 24 hours (M6) after the exercise. For statistical analysis, data was tested for normality and homogeneity of variances. To compare the groups and times in each group, parametric tests (ANOVA) were used for muscular enzymes activity and not parametric tests (Mann-Whitney and Friedmann) were used to analyze blood lactato $(\mathrm{P}<0.05)$. There was no significant difference between groups for any variable. However, within the experimental groups it was possible to observe significant differences between the evaluated moments, in relation to lactate and LDH. In the GTE, significant differences were observed for lactate between M0 and M1, with respective values of $0.90 \mathrm{mmol} / \mathrm{L}$ (min. 0.8, max. 1.6) and $3.65 \mathrm{mmol} / \mathrm{L}$ (min. 1.0, max. 5,7) and for LDH, where the values described in M6 differed significantly from M0, M1, M2, M3 and M4. In the GTR, significant differences between the experimental moments were observed in relation to $\mathrm{LDH}$, and the values observed in M6 were the lowest and differed significantly from those found in M1, M2, M3 and M4. In conclusion, there was no difference between the fitness of animals regularly trained and those trained sporadically. The low magnitude of elevations of serum CK, AST and LDH activity after exercise and the quick return to baseline values, including the blood lactate observed in both groups, suggest that all of evaluated animals were conditioned and able to perform such physical activity.
\end{abstract}

INDEX TERMS: Lactatemia, muscle enzymes, horses, biochemistry, exercise, training, Quarter Horse, team roping, physiology.

\footnotetext{
${ }^{1}$ Recebido em 17 de novembro de 2017.

Aceito para publicação em 24 de novembro de 2017.

${ }^{2}$ Departamento de Clínica, Cirurgia e Reprodução Animal, Faculdade de Medicina Veterinária, Universidade Estadual Paulista (Unesp), Campus de Araçatuba, Rua Clóvis Pestana 793, Bairro Dona Amélia, Araçatuba, SP 16050-680, Brazil. E-mails: bi_gerardi@hotmail.com, daniela_denadai@ hotmail.com, arthur.vt@hotmail.com, joaopedro.vet@gmail.com, jeozanon@ gmail.com, linagomide@gmail.com, luizclaudiomendes@gmail.com; *Autor para correspondência: marijeronymo@hotmail.com
}

RESUMO.- 0 objetivo do trabalho foi avaliar a influência de diferentes tipos de treinamento sobre o condicionamento físico de equinos por meio da determinação do lactato sanguíneo e da atividade sérica de creatina quinase, aspartato aminotransferase e lactato desidrogenase após exercício físico de alta intensidade e curta duração. Amostras de sangue venoso foram obtidas de 16 equinos da raça Quarto de Milha, 
divididos em dois grupos: grupo de treinamento regular (GTR) e grupo de treinamento esporádico (GTE), em sete diferentes momentos: 30 minutos antes do exercício (M0), imediatamente após (M1), 30 minutos (M2), uma (M3), duas (M4), seis (M5) e 24 (M6) horas após o exercício. Para a análise estatística, os dados foram testados quanto à normalidade e homogeneidade de variâncias. Para comparar os grupos e os momentos em cada grupo foram utilizados testes paramétricos (ANOVA) para a análise das atividades séricas das enzimas musculares e não paramétricos (Mann-Whitney e Friedmann) para a análise do lactato sanguíneo $(\mathrm{P}<0,05)$. Não houve diferença significativa entre os grupos para nenhuma variável. No entanto, dentro dos grupos experimentais foi possível observar diferenças significativas entre os momentos avaliados, em relação ao lactato e à LDH. No GTE, foram observadas diferenças significativas quanto ao lactato, entre o M0 e o M1, com valores respectivos de $0,90 \mathrm{mmol} / \mathrm{L}$ (mín. 0,8 - máx. 1,6) e 3,65mmo/L (mín. 1,0 - máx. 5,7) e quanto à LDH, onde os valores descritos no M6 diferiram significativamente de M0, M1, M2, M3 e M4. No GTR, diferenças significativas entre os momentos experimentais foram observadas em relação à $\mathrm{LDH}$, sendo que os valores observados no M6 foram os menores e diferiram significativamente daqueles encontrados no M1, M2, M3 e M4. Em conclusão, não houve diferença entre o condicionamento físico dos animais treinados regularmente e aqueles treinados esporadicamente. A baixa magnitude das elevações das concentrações de CK, AST e LDH após o exercício e o rápido retorno aos valores basais, inclusive do lactato, observados em ambos os grupos, sugere que todos os animais avaliados estavam condicionados e aptos a realizar tal atividade física.

TERMOS DE INDEXAÇ̃̃O: Lactatemia, enzimas musculares, equinos, bioquímica, exercício, treinamento, cavalo Quarto de Milha, laço em dupla.

\section{INTRODUÇÃO}

0 estudo da fisiologia do exercício vem, cada vez mais, se destacando como ferramenta imprescindível no monitoramento da intensidade do treinamento e no aperfeiçoamento de metodologias relacionadas à resistência, força e recuperação desses atletas.

Durante o exercício, a produção e a utilização apropriada de energia são essenciais para a atividade muscular do equino atleta. De uma forma geral, o aumento da concentração de lactato plasmático pode ser utilizado para indicar a intensidade do exercício e o condicionamento físico do animal, visto que animais que apresentam grande capacidade aeróbica geralmente apresentam baixas elevações das concentrações de lactato em resposta ao exercício e uma clearance mais eficiente (Valberg 2008).

Além disso, as enzimas creatina quinase (CK), aspartato-aminotransferase (AST) e lactato desidrogenase (LDH) também participam ativamente da produção de energia em resposta ao exercício, sendo liberadas na circulação como resultado da intensificação da função celular ou como uma reação a lesões (Snow \& Valberg 1994), o que permite que elas sejam comumente utilizadas para avaliação do sistema muscular, da intensidade do exercício e do condicionamento físico dos equinos atletas (Kowal et al. 2006). Existem grandes diferenças na literatura referente aos valores considerados de repouso e valores obtidos após a realização de uma atividade atlética. Isso se deve ao fato de que estas enzimas sofrem influência de diversos fatores tais como raça, idade, tipo e duração do exercício imposto, além de fatores ambientais e de manejo (Câmara e Silva et al. 2007). Brandi et al. (2008) sugerem que a avaliação dos efeitos do exercício físico seja feita através da comparação com o valor basal obtido do próprio animal ou com um grupo de equinos que tenha as mesmas características.

Um treinamento adequado inclui exercícios de várias intensidades e durações (Jones 2005) e deve ter como principais objetivos aumentar a capacidade aeróbica do animal, melhorar o desempenho físico e diminuir os riscos de lesões. A realização de atividades físicas inapropriadas e o improviso no treinamento podem retirar, definitivamente, de trabalhos e competições importantes cavalos atletas e animais promissores nas diversas modalidades equestres (Rose 2000).

Várias pesquisas abordam a fisiologia do exercício equino, envolvendo a avaliação do desempenho de cavalos submetidos a provas funcionais e testes incrementais (Gomide et al. 2006, Thomassian et al. 2007, Lindner 2010, Amaral et al. 2013, Sales et al. 2013, Oliveira et al. 2014, Soares et al. 2014, Wanderley et al. 2015). No entanto, são poucos os trabalhos que envolvem equinos Quarto de Milha usados em provas "western", como as provas de laço em dupla, submetidos a exercícios de alta intensidade e curta duração (Caiado et al. 2011, Coelho et al. 2011, Miranda et al. 2011, Bueno et al. 2012, Ramalho et al. 2012). Da mesma forma, poucos são os estudos que comparam diferentes tipos de treinamento (Marlin 2015).

Tendo em vista a necessidade de maiores informação sobre os parâmetros ligados à fisiologia do exercício de equinos submetidos a provas de alta intensidade e curta duração e a importância da elaboração de formas mais adequadas de treinamento, melhorando assim o condicionamento físico e o desempenho atlético desses animais, objetivou- se, nesse estudo, avaliar as concentrações sanguíneas de lactato e a atividade sérica de creatina quinase, aspartato aminotransferase e lactato desidrogenase, antes e após o exercício, em equinos Quarto de Milha submetidos à prova de laço em dupla, treinados regularmente ou esporadicamente e observar se existe diferença no condicionamento físico desses animais de acordo com o tipo de treinamento ao qual são submetidos.

\section{MATERIAL E MÉTODOS}

Foram utilizados 16 equinos da raça Quarto de Milha, sendo oito fêmeas e oito machos, com idades variando entre três e nove anos e peso médio de $450 \mathrm{~kg}$, considerados clinicamente saudáveis mediante exame clínico e hemograma. 0 presente trabalho foi devidamente avaliado e aprovado pelo Comitê de Ética no Uso de Animais (CEUA, Unesp Campus Araçatuba (Protocolo no 2012-01985).

0 experimento foi conduzido em um centro de treinamento equestre de laço em dupla na região de Araçatuba/SP (latitude $21^{\circ} 18^{\prime} 02^{\prime \prime}$ sul, longitude $50^{\circ} 43^{\prime} 36^{\prime \prime}$ oeste, altitude de 420 metros, clima tropical) onde os animais ficavam alojados em baias individuais e eram alimentados com feno de Tifton e ração comercial peletizada (Equitage Supreme ${ }^{\circledR}$, Guabi, Brasil) duas vezes ao dia, recebiam suplementação mineral uma vez ao dia e água à vontade.

Os 16 equinos foram divididos em dois grupos, de acordo com a frequência de treinamento ao qual eram submetidos: grupo de treino 
regular (GTR) composto por oito equinos, quatro machos e quatro fêmeas, que treinavam cinco dias por semana, com idade média de 3,8 anos $( \pm 0,83)$, e grupo de treino esporádico (GTE) composto por oito equinos, também quatro machos e quatro fêmeas, com idade média de 6 anos $( \pm 1,3)$, os quais treinavam até dois dias por semana. Todos os animais eram submetidos a um programa geral de treinamento semelhante, de mesma intensidade, velocidade e duração, sempre conduzidos pelo mesmo treinador, com diferença apenas quanto à frequência em que eram treinados e passaram por um período de repouso de, no mínimo, 24 horas antes do início do experimento.

Para a avaliação da atividade enzimática e das concentrações de lactato foram coletadas amostras de sangue venoso em momentos predeterminados, divididos em: 30 minutos antes do exercício (M0), imediatamente após (M1), 30 minutos (M2), uma (M3), duas (M4), seis (M5) e 24 (M6) horas após o exercício.

As coletas foram realizadas em situação de simulação de prova, onde os animais foram submetidos à modalidade de laço em dupla, também conhecida por team roping, na qual uma dupla de cavaleiros laça um bezerro, sendo um dos cavaleiros responsável em laçar a cabeça e o outro responsável em laçar os pés. 0 tempo da prova, em média de oito a 10 segundos, decorre desde o momento em que os laçadores saem do boxe até os dois cavaleiros laçarem o bezerro mantendo-o sob a corda esticada e amarrada à sela do cavalo. Vence a dupla que completar a prova em menos tempo. (Caiado et al. 2011). Geralmente, cavalos e cavaleiros fazem várias participações na competição, em busca de melhores resultados.

Foram realizadas duas simulações, em dias diferentes, sempre no período da manhã, entre as 8 e as 11 horas, com temperatura média de 29,2 o e umidade relativa do ar média de $60,2 \%$. As simulações foram executadas dentro do próprio centro de treinamento onde ocorreram as coletas, em pista coberta e de areia. Na primeira simulação participaram metade dos equinos do GTE e metade do GTR e na segunda simulação a outra metade restante de cada grupo. Os animais foram submetidos ao exercício de laço em dupla cinco vezes consecutivas antes que fosse realizada a coleta do M1, sempre conduzidos pela mesma dupla de cavaleiros. As simulações duraram, em média, 15 minutos para cada animal. Todos os animais passaram por um período de aquecimento antes da prova de aproximadamente, 20 minutos, divididos em cinco minutos de exercício ao passo, 10 minutos ao trote e cinco minutos a galope, em um percurso circular de sete metros de diâmetro. Todos os animais foram aquecidos pelo mesmo cavaleiro.

As amostras de sangue venoso foram coletadas através da punção da veia jugular, de forma asséptica, pelo sistema BD Vacutainer ${ }^{\circledR}$ (BD Vacutainer ${ }^{\circledR}$, Nova Jersey, EUA), em frascos de vidro siliconizados sem anticoagulante para as análises bioquímicas. A determinação do lactato sanguíneo foi realizada imediatamente após a coleta, com sangue total, por meio de um analisador clínico eletrônico portátil (Accutrend ${ }^{\circledR}$ Plus, Roche Diagnostics, EUA) utilizando-se cartuchos específicos (Accusport ${ }^{\circledR}$ BM-Lactate, Roche Diagnostics, EUA) conforme as instruções do fabricante. As amostras destinadas aos exames bioquímicos, para a determinação das atividades séricas de CK, AST e LDH, foram adequadamente identificadas e acondicionadas em caixa isotérmica com gelo reciclável e transportadas até o laboratório, onde foram devidamente centrifugadas para obtenção de soro, no mesmo dia das coletas. As amostras de soro foram, então, devidamente armazenadas e posteriormente analisadas em analisador bioquímico semi-automático (TP-Analyzer Basic ${ }^{\circledR}$, Thermoplate, China), em comprimento de onda de $340 \mathrm{~nm}$, por meio de kits bioquímicos específicos para cada enzima (CK-NAC Liquiform,
AST/GOT Liquiform, LDH Liquiform, Labtest ${ }^{\circledR}$, Brasil), seguindo as recomendações do fabricante.

Os resultados obtidos quanto ao lactato sanguíneo foram analisados usando o teste de Mann-Whitney para comparar os grupos em cada momento e o teste de Friedman para comparar os momentos em cada grupo, seguido do teste de Dunn para comparações múltiplas. Os dados obtidos quanto às atividades séricas de CK, AST e LDH foram submetidos à análise de variância com medidas repetidas para comparação entre grupos e momentos, seguido da comparação das médias pelo teste de comparações múltiplas de Tukey no nível de significância de $5 \%$. Os dados foram testados quanto à normalidade e homogeneidade de variâncias, pré-requisitos necessários para a análise de variância. As diferenças foram consideradas significativas quando $\mathrm{P}<0,05$ e as análises foram efetuadas empregando-se o programa SAS (StatisticalAnalysis System) (SAS Institute Inc. The SAS System, release 9.3. SAS Institute Inc, EUA, 2014).

\section{RESULTADOS}

A mediana das concentrações sanguíneas de lactato e os valores mínimo e máximo em cada momento, confrontados entre os dois grupos que foram analisados no presente trabalho, encontram-se no Quadro 1. Não foi encontrada diferença significativa sobre a concentração sanguínea de lactato entre os grupos. No entanto, foram observadas diferenças significativas entre os momentos experimentais, em resposta ao exercício, no GTE, onde a lactatemia registrada no M1 foi significativamente maior do que a encontrada em M0 (repouso). Além disso, a partir do M2 é possível notar um rápido declínio das concentrações de lactato, em ambos os grupos.

No Quadro 2, estão expressos os valores médios e desvios-padrão para as atividades séricas de CK, AST e LDH encontrados em cada momento, confrontados entre os dois grupos avaliados. Não foram observadas diferenças significativas entre os grupos para as atividades séricas de CK, AST e LDH. Entretanto, dentro de ambos os grupos experimentais, foram encontradas diferenças significativas nas atividades séricas de

Quadro 1. Valores da mediana (Md) e valores máximos (Máx) e mínimos (Mín) das concentrações séricas de lactato em mol/L, de equinos submetidos à prova de laço em dupla, nos momentos antes e após o exercício, divididos em GTR (grupo de treino regular) e GTE (grupo de treino esporádico)

\begin{tabular}{|c|c|c|c|c|c|c|}
\hline \multirow{2}{*}{ Variável } & \multirow{2}{*}{ Momentos } & \multicolumn{2}{|c|}{ GTR } & \multicolumn{3}{|c|}{ GTE } \\
\hline & & Md & Mín - Máx & $\mathrm{Md}$ & Mín - Máx & \\
\hline \multirow{7}{*}{$\begin{array}{c}\text { Lactato } \\
(\mathrm{mmol} / \mathrm{L})\end{array}$} & $\mathrm{M}_{0}$ & 1,15 & $0,8-2,1$ & 0,9 & $0,8-1,6$ & $\mathrm{~b}$ \\
\hline & $\mathrm{M}_{1}$ & 2,55 & $1,0-3,3$ & 3,65 & $1,0-5,7$ & a \\
\hline & $\mathrm{M}_{2}$ & 1,2 & $0,9-2,4$ & 1,65 & $1,2-3,3$ & $\mathrm{ab}$ \\
\hline & $\mathrm{M}_{3}$ & 1,2 & $0,8-1,4$ & 1,35 & $0,9-2,5$ & $\mathrm{ab}$ \\
\hline & $\mathrm{M}_{4}$ & 1,4 & $1,0-2,0$ & 1,3 & $0,9-2,6$ & $\mathrm{ab}$ \\
\hline & $\mathrm{M}_{5}$ & 1,55 & $0,9-2,5$ & 1,25 & $0,8-3,8$ & $\mathrm{ab}$ \\
\hline & $\mathrm{M}_{6}$ & 1,4 & $0,8-2,3$ & 1,15 & $0,8-2,1$ & $\mathrm{ab}$ \\
\hline
\end{tabular}

* Letras minúsculas diferentes na mesma coluna denotam diferença significativa entre os momentos $(\mathrm{p}<0,05)$, pelo teste de Friedman. M0 = Repouso, 30 minutos antes da prova, $\mathrm{M} 1=$ imediatamente após a prova, M2 = 30 minutos após a prova, M3 = uma hora após a prova, M4 = duas horas após a prova, M5 = seis horas após a prova e M6 = 24 horas após a prova. 
Quadro 2. Valores médios e desvios-padrão das concentrações séricas de creatina quinase (CK), aspartato aminotransferase (AST) e lactato desidrogenase (LDH), em UI/L, de equinos submetidos à prova de laço em dupla, nos momentos antes e após o exercício, divididos em GTR (grupo de treino regular) e GTE (grupo de treino esporádico)

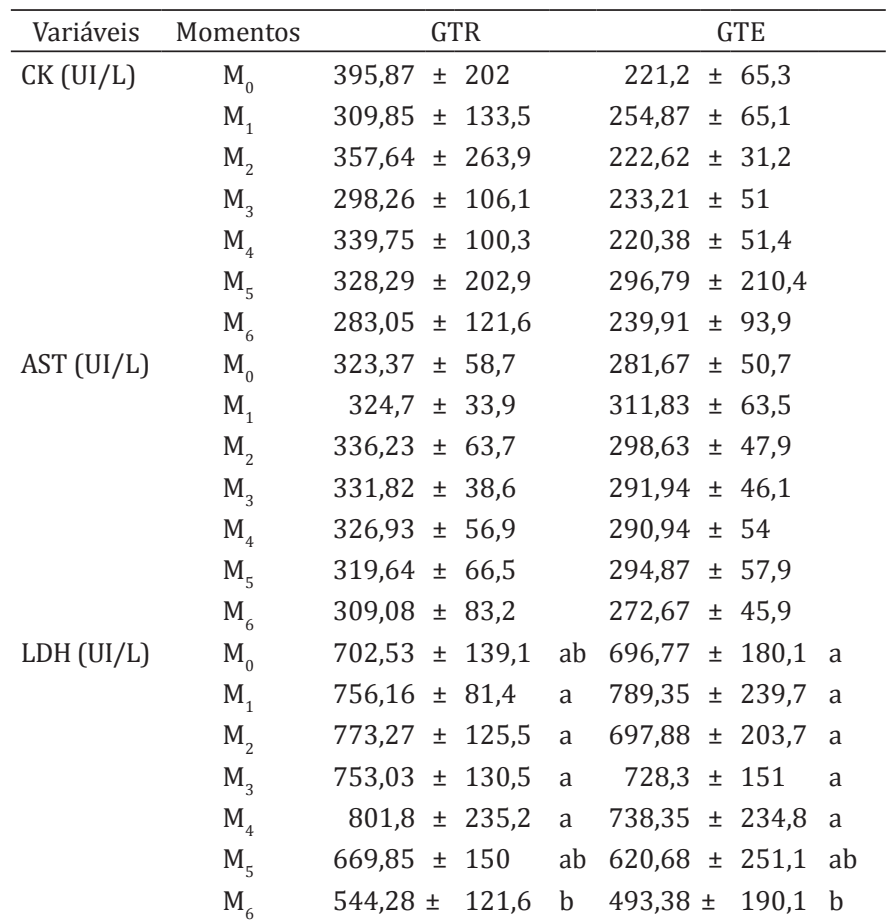

* Letras minúsculas diferentes na mesma coluna denotam diferença significativa entre os momentos $(\mathrm{p}<0,05)$, pelo teste de Tukey. M0 (repouso, 30 minutos antes da prova), M1 (imediatamente após a prova), M2 (30 minutos após a prova), M3 (uma hora após a prova), M4 (duas horas após a prova), M5 (seis horas após a prova) e M6 (24 horas após a prova).

LDH entre os momentos. No GTR, o valor de M6 foi o menor encontrado, diferindo significativamente dos momentos M1, M2, M3 e M4. No GTE, novamente o valor de M6 foi o menor, diferindo, dessa vez, de M0, M1, M2, M3 e M4.

\section{DISCUSSÃO}

Um programa ideal de treinamento é caracterizado por submeter os equinos a exercícios com intensidade e duração corretas e, principalmente, com uma frequência que permita que o animal tenha tempo suficiente para se recuperar entre os períodos de atividade física, mas que resulte em respostas fisiológicas do organismo frente ao exercício. Treinamentos com frequências baixas podem não gerar respostas adaptativas, enquanto frequências altas podem aumentar os riscos de lesões associadas ao esporte (Marlin \& Nankervis 2002). Embora já tenham sido realizados vários estudos sobre treinamento, esta é uma área que poderia se beneficiar de investigações mais aprofundadas. Especificamente, há poucos estudos que comparam diferentes tipos de treinamento (Marlin 2015), principalmente relacionados à frequência. Além disso, ainda não é comum encontrar trabalhos na literatura que explorem metodologias de experimento à campo, avaliando equinos da raça Quarto de Milha utilizados em provas de alta intensidade e curta duração (Lopes et al. 2009, Caiado et al. 2011, Coelho et al. 2011, Miranda et al. 2011, Bueno et al. 2012, Ramalho et al. 2012), como foi realizado no presente trabalho.

Os resultados mostraram não haver diferença significativa entre os grupos estudados, em nenhuma das variáveis analisadas. No entanto, foram observadas alterações significativas entre os momentos, dentro dos grupos experimentais, em resposta ao exercício, com as principais alterações sendo observadas em relação à concentração sanguínea de lactato. No GTE houve diferença significativa entre o M0 e M1, sendo a concentração sanguínea de lactato no M1, imediatamente após o exercício, maior que a concentração obtida no repouso (M0), respectivamente 3,65mmol/L (mín. 1,0 - máx. 5,7) e 0,90mmol/L (mín. 0,80 - máx. 1,6). Da mesma forma, Caiado et al. (2011) e Bueno et al. (2012), que trabalharam, respectivamente com, equinos Quarto de Milha de laço em dupla e competidores de Três Tambores, relataram aumento significativo dos valores de lactato após o exercício. A elevação na concentração de lactato após atividade física é esperada, pois todas as fontes de energia são ativadas (McGowan 2008). Nos exercícios de alta intensidade e curta duração as principais vias metabólicas para produção de energia são anaeróbicas, primeiro com a utilização dos estoques de fosfocreatina e depois com a glicólise anaeróbica, com consequente formação de lactato. Além disso, equinos Quarto de Milha possuem alta proporção de fibras musculares do tipo II, importantes para exercícios de alta intensidade e curta duração por terem capacidade de contração rápida e maior potencial glicolítico (Eaton 1998, Hodgson et al. 2014). Em resposta ao treinamento, o organismo passa por adaptações fisiológicas que levam a uma diminuição progressiva das concentrações sanguíneas de lactato após o exercício, dentre essas adaptações estão o aumento da capacidade em metabolizar o lactato e o aumento na proporção de fibras IIA:IIX, já que as fibras do tipo IIA possuem melhor capacidade oxidativa ( Santiago et al. 2013). Sendo assim, a determinação do lactato após o exercício permite determinar o nível de esforço físico aos quais os equinos foram submetidos, bem como determinar o preparo dos referidos animais para realizar o exercício imposto (Gomide et al. 2006). A não ocorrência de diferença significativa entre os mesmos momentos no GTR pode sugerir que os animais deste grupo estavam mais bem preparados para o tipo de exercício realizado do que os animais do GTE.

A concentração de lactato está relacionada à intensidade do exercício, possibilitando avaliar o sistema de produção energética mais utilizado (Desmecht et al. 1996). Além disso, é uma variável de fácil aferição, mesmo em condições de campo (Courocé 1998), já que o uso de analisadores portáteis para mensuração de lactato é perfeitamente recomendado e tem sido amplamente empregado nos trabalhos que avaliam o exercício equino, não apresentando resultados diferentes daqueles obtidos através de métodos laboratoriais, principalmente quando as concentrações sanguíneas de lactato não ultrapassam $13 \mathrm{mmol} / \mathrm{L}$, como foi observado no presente trabalho. Além disso, a mensuração no sangue total, como foi realizada no presente trabalho, apresenta melhor correlação que no plasma com o Accusport ${ }^{\circledR}$, sugerindo eficiência na fórmula de correção utilizada pelo aparelho, para equinos (Evans \& Golland 1996, Lindner 1996, Simmons et al. 1999, 
Lindner et al. 2009, Lindner et al. 2011, Assenza et al. 2014, Munsters et al. 2014, Duarte et al. 2015, Sommer et al. 2015).

0 Limiar de lactato (LL) ou limiar aeróbico (LA) refere-se ao ponto onde, com o incremento da intensidade do exercício, o lactato começa a se acumular, pelo aumento no metabolismo anaeróbico (Courocé 1998). Em 1976, Mader et al. determinaram um LL de $4 \mathrm{mmol} / \mathrm{L}$ para humanos, sendo chamado de $\mathrm{V}_{4} \mathrm{e}$ definido como a velocidade onde a concentração de lactato atinge $4 \mathrm{mmol} / \mathrm{L}$, o que significava que, quanto maior a $\mathrm{V}_{4}$, maior a capacidade aeróbica do indivíduo. Nos anos 80, esse limiar passou a ser adotado para o uso em equinos (Snow 1987). Sendo assim, considerando o LL de $4 \mathrm{mmol} / \mathrm{l}$ e com os valores obtidos imediatamente após o exercício, neste trabalho, ficando abaixo deste limiar, seria possível considerar que houve predominância do metabolismo aeróbico e que, consequentemente, o exercício imposto foi de intensidade moderada, o que contraria o presente trabalho, que trata de um exercício de alta intensidade. Porém, atualmente, alguns trabalhos vem desenvolvendo e utilizando novas formas de definir o LL em equinos (Gondim et al. 2007, Lindner 2010, Soares et al. 2014). Um dos métodos mais populares, considerado como o "padrão ouro" para a determinação do LL, é a chamada MFEL (máxima fase estável de lactato), definida como a intensidade do exercício onde há um equilíbrio entre a produção e a remoção do lactato sanguíneo (Lindner 2010). Por meio da utilização desse método, Lindner (2010) determinou o LL sendo 1,5mmol/L, muito abaixo do pré-estabelecido $4 \mathrm{mmol} / \mathrm{L}$. Da mesma forma, Soares et al. (2014), relatou valores para o LL entre $0,74 \pm 0,33 \mathrm{mmol} / \mathrm{L}$ e 1,69 $\pm 0,93 \mathrm{mmol} / \mathrm{L}$, com média de $0,84 \pm 0,20 \mathrm{mmol} / \mathrm{L}$. Tais valores são bem inferiores aos encontrados imediatamente após o exercício no presente trabalho $(2,55 \mathrm{mmol} / \mathrm{L} \mathrm{e} 3,65 \mathrm{mmol} / \mathrm{L})$, o que permite determinar que houve metabolismo anaeróbico e, portanto, o exercício imposto foi, realmente, de alta intensidade.

Assim como as concentrações de lactato mensuradas após o exercício, o tempo de retorno do lactato sanguíneo aos valores basais também pode ser utilizado para avaliar o efeito do treinamento sobre o condicionamento físico. Equinos bem condicionados tendem a apresentar melhores taxas de remoção de lactato (Gama et al. 2012). 0 retorno das concentrações sanguíneas de lactato aos valores basais, 30 minutos após a realização do exercício, observado neste trabalho em ambos os grupos pode indicar um efeito positivo do treinamento sobre o condicionamento físico dos animais (Zobba et al. 2011, Santiago et al. 2013, Assenza et al. 2014).

A atividade sérica de CK atinge o pico de 6-12 horas após a lesão ou esforço muscular, voltando aos valores basais 3-4 dias depois, se o insulto ou a lesão não voltarem a ocorrer (Cardinet et al. 1967). A avaliação da atividade sérica de CK nos diferentes momentos, em resposta ao exercício, não demonstrou diferenças significativas, mesmo nos momentos que correspondem ao seu pico, em nenhum dos grupos abordados no presente trabalho. Segundo Thomassian et al. (2007), aumentos de menor magnitude ou a não interferência nos valores de CK, seriam resultados esperados após atividade física em equinos bem condicionados.

Semelhante ao que foi encontrado na avaliação da atividade de $\mathrm{CK}$, não foi possível observar diferença significativa entre os diferentes momentos de avaliação da atividade sérica de AST em ambos os grupos, corroborando com o encontrado por Balarin et al. (2005) e Caiado et al. (2011), que descreveram que os valores séricos desta enzima não apresentaram diferença significativa em resposta ao exercício, em equinos submetidos a exercício de alta intensidade, após passarem por um período mínimo de treinamento de 12 meses. Segundo Câmara e Silva et al. (2007) o aumento após o exercício seria influenciado pela fase do treinamento e pelo tipo de exercício, portanto, equinos treinados e condicionados à atividade física imposta teriam uma menor magnitude de aumento na AST sérica. No entanto, a AST apresenta o pico de sua atividade sérica 24-48 horas depois da lesão muscular ou esforço físico intenso (Zobba et al. 2011), e, no presente trabalho, não foram realizadas coletas após as 24 horas, dificultando a real compreensão do comportamento de sua atividade frente ao exercício imposto e a posterior comparação entre os grupos estudados.

Em relação às concentrações séricas de LDH obtidas, diferente de CK e AST, foram observadas diferenças significativas entre os momentos avaliados, tanto no GTR quanto no GTE. Em ambos os grupos, os valores encontrados em M6, ou seja, 24 horas após o exercício, foram os menores valores e, por isso, diferiram dos demais momentos. Tal fato, provavelmente, corresponde à recuperação dos animais frente ao exercício (Oliveira et al. 2014). Os valores séricos de LDH em equinos diminuem de forma progressiva à medida que o animal melhora o seu condicionamento, se adaptando à atividade física imposta (Rudolph et al. 1993).

\section{CONCLUSÕES}

Com base nos resultados obtidos, conclui-se que não houve diferença no condicionamento físico entre os equinos treinados regularmente e os equinos treinados esporadicamente.

A baixa magnitude de elevação ou a não observação de alterações significativas nos parâmetros estudados, após o exercício, e o rápido retorno aos valores basais, principalmente em relação à concentração sanguínea de lactato, notados em ambos os grupos, sugere que todos os animais estavam adaptados ao tipo de exercício ao qual foram submetidos e estão aptos e condicionados para realizar tal atividade física.

Agradecimentos.- À Fundação de Amparo à Pesquisa do Estado de São Paulo (FAPESP), pelo apoio financeiro. Processo 2014/09362-5.

\section{REFERÊNCIAS}

Amaral L.A., Torres A., Rabassa V., Martins C.F., Correa M.N. \& Nogueira C.E.W. 2013. Limiar anaeróbico (V4) e frequência cardíaca de cavalos Crioulos condicionados para prova funcional. Arq. Bras. Med. Vet. Zootec. 65(1):181188. <http://dx.doi.org/10.1590/S0102-09352013000100027>

Assenza A.A., Bergero D., Congiu F., Tosto F., Giannetto C. \& Piccione G. 2014. Evaluation of serum electrolytes and blood lactate concentration during repeated maximal exercise in horse. J. Equine Vet. Sci. 34(10):1175-1180. <http://dx.doi.org/10.1016/j.jevs.2014.07.001>

Balarin M.R.S., Lopes R.S., Kohayagawa A., Laposy C.B. \& Fonteque J.H. 2005. Avaliação da glicemia e da atividade sérica de aspartato aminotransferase, creatinoquinase, gama-glutamiltransferase e lactato desidrogenase em equinos puro sangue inglês (PSI) submetidos a exercícios de diferentes intensidades. Semina, Ciênc. Agrárias 26(2):211-218.

Brandi R.A., Furtado C.E., Martins E.N., Freitas E.V.V., Lacerda-Neto J.C. \& Queiroz-Neto A. 2008. Efeito de dietas com adição de óleo e do treinamento sobre a atividade muscular de equinos submetidos à prova de resistência. Acta Scient., Anim. Sci. 30(3):307-315. <http://dx.doi.org/10.4025/ actascianimsci.v30i3.5714> 
Bueno G.M., Bernardo N., Dias D., Gomide L., Gravena K. \& Lacerda Neto J.C. 2012. Curva lactacidêmica em equinos da raça Quarto-de-milha durante a realização da prova dos três tambores. Revta Educ. Cont. Vet. Med. Zootec. 10(1):80-81.

Caiado J.C.C., Pissinate G.L., Souza V.R.C., Fonseca L.A. \& Coelho C.S. 2011. Lactacidemia e concentrações séricas de aspartato aminotransferase e creatinoquinase em equinos da raça Quarto de Milha usados em provas de laço em dupla. Revta Pesq. Vet. Bras. 31(5):452-458. <http://dx.doi. org/10.1590/S0100-736X2011000500014>

Câmara e Silva I.A., Dias R.V.C. \& Soto-Blanco B. 2007. Atividades séricas de creatina quinase, lactato desidrogenase e aspartato aminotransferase em equinos de diferentes categorias de atividade. Arq. Bras. Med. Vet. Zootec. 59(1):250-252. <http://dx.doi.org/10.1590/S0102-09352007000100041>

Cardinet G.H., Littrell J.F. \& Freedland R.A. 1967. Comparative investigations of serum creatine phosphokinase and glutamic-oxaloacetic transaminase activities in equine paralytic myoglobinuria. Res. Vet. Sci. 8(2):219-226. $<$ PMid:6068600>

Coelho C.S., Lopes P.F.R., Pissinate G.L., Ramalho L.O. \& Souza V.R.C. 2011. Influence of physical exercise on serum electrolytes in Quarter horses submitted to team roping. Revta Bras. Ciênc. Vet. 18(1):32-35.

Courocé A. 1998. Endurance and sprint training. Anais Conference on Equine Sports Medicine and Science, Cordoba, Espanha. Pers., Wageningen, The Netherlands, p.190-202. (Resumo)

Desmecht D., Linden A., Amory H., Art T. \& Lekeux P. 1996. Relationship of plasma lactate production to cortisol release following completion of different types of sporting events in horses. Vet. Res. Commun. 20(4):371379. PMID: 8865580.

Duarte P.C., Souza R.F., Almeida R.M., Balsamão G.M., Ferraz G.C. \& Teixeira Neto A.R. 2015. Evaluation of energetic metabolism of horses in longdistance exercise: Accutrend ${ }^{\circledast}$ Plus versus laboratory. Comp. Clin. Pathol. 24(2):311-315. <http://dx.doi.org/10.1007/s00580-014-1900-3>

Eaton M.D. 1998. Energetics and performance, p.49-62. In: Hodgson D.R. \& Rose R.J. (Eds), The Athletic Horse: principles and practice of equine sports medicine. W.B. Saunders, Philadelphia.

Evans D.L. \& Golland L.C. 1996. Accuracy of accusport for measurement of lactate concentrations in equine blood and plasma. Equine Vet. J. 28(5):398-402.<http://dx.doi.org/10.1111/j.2042-3306.1996.tb03111. $\mathrm{x}><$ PMid:8894538>

Gama J.A.N., Souza M.S., Pereira Neto E., Souza V.R.C. \& Coelho C.S. 2012. Concentrações séricas de aspartato aminotransferase e creatinoquinase e concentrações plasmáticas de lactato em equinos da raça Mangalarga Marchador após exercício físico. Braz. J. Vet. Res. Anim. Sci. 49(6):480-486. <http://dx.doi.org/10.11606/issn.1678-4456.v49i6p480-486>

Gomide L.M.W., Martins C.B., Orozco C.A.G., Sampaio R.C.L., Belli T., Baldissera V. \& Lacerda Neto J.C. 2006. Concentrações sangüíneas de lactato em eqüinos durante a prova de fundo do concurso completo de equitação. Ciência Rural 36(2):509-513. <http://dx.doi.org/10.1590/S0103-84782006000200022>

Gondim F.J., Zoppi C.C., Pereira-da-Silva L. \& Macedo D.V. 2007. Determination of the anaerobic threshold and maximal lactate steady state speed in equines using the lactate minimum speed protocol. Comp. Biochem. Physiol. A, Mol. Integr. Physiol. 146(3):375-380. <http://dx.doi.org/10.1016/j. cbpa.2006.11.002><PMid:17234441>

Hodgson D.R., McKeever K.H. \& McGowan C.M. 2014. The athletic horse: principles and practice of equine sports medicine. 2 nd ed. W.B. Saunders, Missouri. 397p.

Jones E.W. 2005. Scientific training. J. Equine Vet. Sci. 25(7):320-321.<http:// dx.doi.org/10.1016/j.jevs.2005.06.014>

Kowal R.J., Almosny N.R.P., Cascardo B., Summa R.P. \& Cury L.J. 2006. Avaliação dos valores de lactato e da atividade sérica da enzima creatina quinase em cavalos (Equus caballus) da raça Puro-Sangue-Inglês (PSI) submetidos a teste de esforço em esteira ergométrica. Revta Bras. Ciên. Vet. 13(1):13-19.
Lindner A. 1996. Measurement of plasma lactate concentration with Accusport. Equine Vet. J. 28(5):403-405.<http://dx.doi.org/10.1111/j.2042-3306.1996. tb03112.x><PMid:8894539>

Lindner A., López R.A., Durante E., Ferreira V. \& Boffi Federico F.M. 2009. Conditioning horses at v10 3 times per week does not enhance v4. J. Equine Vet. Sci. 29(12):828-832. <http://dx.doi.org/10.1016/j.jevs.2009.10.012>

Lindner A., Signorini R., Brero L., Arn E., Mancini R. \& Enrique A. 2011. Effect of conditioning horses one, two or three times a week with 2 runs of 100 meters at near maximal speed on v4. J. Equine Vet. Sci. 31(5/6):238-239. $<$ http://dx.doi.org/10.1016/j.jevs.2011.03.035>

Lindner A.E. 2010. Maximal lactate steady state during exercise in blood of horses. J. Anim. Sci. 88(6):2038-2044. <http://dx.doi.org/10.2527/ jas.2009-2693><PMid:20190168>

Lopes K.R.F., Batista J.S., Dias R.V.C. \& Soto-Blanco B. 2009. Influência das competições de vaquejada sobre os parâmetros indicadores de estresse em equinos. Ciênc. Anim. Bras. 10(2):538-543.

Mader A., Liesen H., Heck H., Phillippi H., Rost R. \& Schürch P. 1976. Zur Beurteilung der sportartspeziefischen Ausdauerleistungsfähigkeit im Labor. Sport Sportmed. 27:80-88.

Marlin D. 2015. Has the golden age of equine exercise physiology passed and if so, have we answered all the big questions? J. Equine Vet. Sci. 35(5):354360. <http://dx.doi.org/10.1016/j.jevs.2015.03.006>

Marlin D. \& Nankervis K. 2002. Equine Exercise Physiology. Blackwell Science, Oxford. 296p.

McGowan C. 2008. Clinical pathology in the racing horse: the role of clinical pathology in assessing fitness and performance in the racehorse. Vet. Clin. N. Am., Equine Pract. 24(2):405-421, vii. <http://dx.doi.org/10.1016/j. cveq.2008.03.001><PMid:18652962>

Miranda R.L., Mundim A.V., Saquy A.C.S., Costa A.S., Guimarães E.C., Gonçalves F.C. \& Carneiro e Silva F.0. 2011. Perfil hematológico de equinos submetidos à prova de Team Penning. Pesq. Vet. Bras. 31(1):81-86. http://dx.doi. org/10.1590/S0100-736X2011000100013.

Munsters C.C.B.M., van Iwaarden A., van Weeren R. \& Sloet van OldruitenborghOosterbaan M.M. 2014. Exercise testing in Warmblood sport horses under field conditions. Vet. J. 202(1):11-19. <http://dx.doi.org/10.1016/j. tvjl.2014.07.019><PMid:25172838>

Oliveira C.A.A., Azevedo J.F., Miranda A.C.T., Souza B.G., Ramos M.T., Costa A.P.D., Baldani C.D., Silva V.P. \& Almeida F.Q. 2014. Hematological and blood gas parameters' response to treadmill exercise test in eventing horses fed different protein levels. J. Equine Vet. Sci. 34(11/12):1279-1285. <http:// dx.doi.org/10.1016/j.jevs.2014.09.007>

Ramalho L.O., Caiado J.C.C., Souza V.R.C. \& Coelho C.S. 2012. Glicemia e concentrações séricas de insulina, triglicérides e cortisol em equinos da raça Quarto de Milha e mestiços usados em provas de laço em dupla. Braz. J. Vet. Res. Anim. Sci. 49(4):318-324.<http://dx.doi.org/10.11606/ issn.1678-4456.v49i4p318-324>

Rose R. 2000. Programas de Entrenamiento para Caballos: formas de alcanzar um caballo deportivo. $4^{\mathrm{a}}$ ed. Inter-médica, Buenos Aires, p.27-29.

Rudolph W., Goic M., Matta S. \& Segovia P. 1993. Variación de las isoenzimas de hidrogenasa láctica posterior a um ejercicio en equinos fina sangre de carrera con diferentes períodos entrenamiento. Arch. Med. Vet. 25:57-65.

Sales J.V.F., Dumont C.B.S., Leite C.R., Moraes J.M., Godoy R.F. \& Lima E.M.M. 2013. Expressão do Mg+2, CK, AST e LDH em equinos finalistas de provas de enduro. Pesq. Vet. Bras. 33(1):105-110. <http://dx.doi.org/10.1590/ S0100-736X2013000100019>

Santiago J.M., Almeida F.Q., Silva L.L.F., Miranda A.C.T., Azevedo J.F., Oliveira C.A.A. \& Carrilho S.S. 2013. Hematologia e bioquímica sérica de equinos de concurso completo de equitação em treinamento. Arq. Bras. Med. Vet. Zootec. 65(2):383-392.<http://dx.doi.org/10.1590/S0102-09352013000200013> 
Simmons D.B., Stewart A.W., Stewart C., Pedlef P. \& Roberts P. 1999. A comparative evaluation of the accusport vs. conventional assay methods for the determination of lactate in equine plasma. J. Equine Vet. Sci. 19(6):402-407. <http://dx.doi.org/10.1016/S0737-0806(99)80305-0>

Snow D.H. 1987. Assessment of fitness in the horse. Vet. Clin. N. Am., Equine Pract. 9:26-30.

Snow D.H. \& Valberg S.J. 1994. Muscle anatomy, physiology and adaptations to exercise and training, p.145-179. In: Hodgson D.R. \& Rose R.J. (Eds), The Athletic Horse. W.B. Saunders, Philadelphia.

Soares O.A.B., Ferraz G.C., Martins C.B., Dias D.P.M., Lacerda Neto J.C. \& Queiroz-Neto A. 2014. Comparison of maximal lactate steady state with V2, V4, individual anaerobic threshold and lactate minimum speed in horses. Arq. Bras. Med. Vet. Zootec. 66(1):39-46. <http://dx.doi.org/10.1590/ S0102-09352014000100007>

Sommer L.H., Munk R., Nielsen S.M. \& Lindner A. 2015. Training of horses used for show jumping and its effect on v4. J. Equine Vet. Sci. 35(4):301308. <http://dx.doi.org/10.1016/j.jevs.2015.01.021>
Thomassian A., Carvalho F.D., Watanabe M.J., Silveira V.F., Alves A.L.G., Hussni C.A. \& Nicoletti J.L.M. 2007. Atividades séricas da aspartato aminotransferase, creatina quinase e lactato desidrogenase de eqüinos submetidos ao teste padrão de exercício progressivo em esteira. Braz. J. Vet. Res. Anim. Sci. 44(3):183-190. <http://dx.doi.org/10.11606/issn.16784456.bjvras.2007.26637>

Valberg S.J. 2008. Skeletal muscle function, p.459-484. In: Kaneko J.J., Harvey J.W. \& Bruss M.L. (Eds), Clinical Biochemistry of Domestic Animals. 6th ed. Academic, London. <http://dx.doi.org/10.1016/B978-0-12-3704917.00015-5>

Wanderley E.K., Bem B.S.C., Melo S.K.M., Gonzalez J.C., Manso H.E.C.C. \& Manso Filho H.C. 2015. Hematological and biochemical changes in Mangalarga Marchador horses after a four-beat gait challenge in three different distances. J. Equine Vet. Sci. 35(4):259-263. <http://dx.doi.org/10.1016/j. jevs.2015.01.009>

Zobba R., Ardu M., Niccolini S., Cubeddu F., Dimauro C., Bonelli P., Dedola C., Visco S. \& Parpaglia M.L.P. 2011. Physical, hematological, and biochemical responses to acute intense exercise in polo horses. J. Equine Vet. Sci. 31(9):542-548. <http://dx.doi.org/10.1016/j.jevs.2011.03.010> 